\title{
Collaborative Project-Based Learning Capstone for Engineering and Engineering Technology Students
}

\section{Dr. Andrew P. Ritenour, Western Carolina University}

Andrew Ritenour is currently an Assistant Professor in the School of Engineering + Technology at Western Carolina University (WCU). Prior to joining WCU in 2018, he spent a decade in industry managing and developing innovative technologies across a broad spectrum of applications: high voltage transistors for energy-efficient power conversion, radio frequency (RF) surface acoustic wave (SAW) filters for mobile phones, and flexible paper-like displays for e-readers. He holds 31 patents related to semiconductor devices and microfabrication. His current research interests include instrumentation for combustion science, novel methods for environmental remediation, and microelectronics including surface acoustic wave (SAW) devices. In addition to teaching in the field of electrical engineering, he coordinates the senior engineering capstone program which is a multidisciplinary, two-semester course sequence with projects sponsored by industrial partners. Within this role, he focuses on industrial outreach and the teaching and assessment of professional skills. He received his Ph.D. and S.M. degrees from MIT in 2007 and 1999 , respectively, and a B.S.E.E. degree from the University of Virginia in 1997.

\section{Dr. Chip W Ferguson, Western Carolina University}

Chip Ferguson is the Associate Dean of the College of Engineering and Technology and Professor of Engineering and Technology at Western Carolina University.

\section{Dr. Patrick Gardner, Western Carolina University}

Dr. Gardner is the Director of the Rapid Center in the College of Engineering and Technology at Western Carolina University, providing engineering design, prototyping and testing services for industry partners. $\mathrm{He}$ is the Mountaintop Distinguished Professor in the College. Dr. Gardner is a retired Lt. Colonel, U.S. Air Force and has 30+ years of experience spanning government service, industry and academia.

\section{Mr. Brett Ronald Banther, Western Carolina University}

Brett Banther is currently a Center Project Engineer for the Rapid Center at Western Carolina University (WCU). He is responsible for providing mechanical design, fabrication, and product development assistance, covering wide-ranging applications, to local industry partners and entrepreneurs. In addition, he is involved with the coordination and instruction of the engineering capstone program within the College of Engineering and Technology. The program is a multidisciplinary, two-semester course sequence with projects sponsored by industrial partners.

In 2014, he co-founded a business that designs and produces consumer goods that are sold internationally, and continues to oversee the manufacturing processes. Prior to joining WCU in 2011, he worked in industry designing innovative and award winning tactical knives and firearms. He is a co-inventor on three patent applications related to medical devices and consumer products. He received his M.S and B.A degrees from WCU in 2009 and 2006, respectively.

\section{Dr. Jeffrey L. Ray, Western Carolina University}

Jeffrey L. Ray, F.ASEE has been Dean of the College of Engineering and Technology at Western Carolina University since 2014. Prior to this appointment he was Dean of the School of Engineering Technology and Management and Professor of Mechanical Engineering Technology at Southern Polytechnic State University (SPSU) in Marietta, Georgia beginning in 2007. Prior to joining SPSU, he was the Director of the School of Engineering and Professor of Mechanical Engineering at Grand Valley State University for ten years, in addition to leading the multidisciplinary industry-sponsored capstone design courses. Before joining Grand Valley State University he was an Assistant Professor of Mechanical Engineering at Youngstown State University. His degrees include both B.S. and M.S. degrees in Mechanical Engineering from Tennessee Technological University and a Ph.D. from Vanderbilt University. While at Vanderbilt 
he worked for the Vanderbilt University Department of Orthopaedics performing skeletal biodynamics research. Before beginning engineering school he completed an apprenticeship and was awarded the title of Journeyman Industrial Electrician.

Ray has been an active member at both national and sectional levels. He joined ASEE in 1994. He currently serves as Chair of the Engineering Technology Council and Vice-President, Institutional Councils. Other service includes being a member of the Frederick J Berger awards committee; National Teaching awards committee, and the ASEE Bylaws and Constitution committee. He has served as a member of the Engineering Technology Council board since 2008. Additionally, Ray has been a reviewer, moderator, and author in the Engineering Technology Division and other ASEE divisions at both the national and sectional levels since joining the society. His awards include two Best Session awards at the Conference on Industry Education Collaboration in 2008 and 2013, respectively. In 2009, he served as the Chair of the Southeastern Section annual conference.

Working as a faculty member, administrator, and volunteer for ASEE, and other professional societies, for the past twenty years, Ray has had the opportunities to develop leadership, and other, skills directly applicable to the position of PIC II Chair. Being an active member of ASEE at all levels has been a very exciting and rewarding experience. Ray has worked collaboratively with both ASEE members and staff personnel to move the society forward. 


\title{
Collaborative Project-Based Learning Capstone for Engineering and Engineering Technology Students
}

\begin{abstract}
A highly innovative, industry-sponsored two-semester Capstone course sequence is offered at Western Carolina University. The Capstone courses are the culmination of an interdisciplinary Project-Based Learning (PBL) curricula spanning all four years inclusive of both engineering and engineering technology students. During their 1st year PBL course, students are introduced to basic professional skills including oral and written communications, project management, design methodologies, and other needed skills culminating in a semester project. These concepts are reinforced during the 2 nd and 3 rd year PBL courses with more in-depth professional skills and open-ended design projects. The PBL sequence prepares students for more open-ended and mature Capstone projects during their final year. Providing a common PBL sequence for engineering and engineering technology students allows for peer-to-peer mentorship, where students teach and learn from each other, and replicates the actual work environment they will experience upon graduation.

This paper reviews the PBL course sequence with specific emphasis on design and execution of the two-semester senior Capstone project. Specific examples of projects completed for industry sponsors are provided. Sponsorship data from 2015-2019 is analyzed to determine which industry groups have been engaged in the Capstone program and what categories of projects have been sponsored (e.g. Process Improvement, Automation, Test and Instrumentation, Prototype Development, and Engineering Analysis). The composition of Capstone teams is also analyzed over the same time period to quantify the percentage of teams with interdisciplinary combinations (engineering technology and engineering students) and assess whether team composition was dependent on project category. Student and faculty perceptions of the performance of interdisciplinary teams are summarized. The results suggest that certain categories of projects are best suited for interdisciplinary teams (Automation, Test and Instrumentation, and Prototype Development) while others (Process Improvement and Engineering Analysis) align more closely with engineering technology or engineering teams. Important considerations for interdisciplinary capstone programs team are discussed.
\end{abstract}

\section{Introduction}

The College of Engineering and Technology at Western Carolina University is composed of two (2) academic Schools and an economic development and prototyping design Center. The School of Engineering + Technology contains ABET accredited EAC and ETAC programs housed together in one academic unit. There are currently four (4) programs: Bachelor of Science in Electrical Engineering, Bachelor of Science in Engineering with Concentrations in Mechanical and Electric Power, Bachelor of Science in Electrical and Computer Engineering Technology, and a Bachelor of Science in Engineering Technology with a Concentration in Applied Systems Technology.

A hallmark of our collaborative approach to engineering and engineering technology programs, housed in the same School, is pairing our more theoretical engineering programs with our more 
applied engineering technology programs through our Project-Based Learning (PBL) course sequence beginning in the students' first semester and continuing throughout all four years of the curricula, as described below. A second unique approach is that faculty teach in both the engineering and engineering technology programs as well as our PBL courses.

According to Richard Vaz, Director of the Center for Project-Based Learning at Worcester Polytechnic Institute, PBL is considered a high-impact education practice. He states "They promote active engagement, requiring students to spend considerable time on task. They involve collaboration, both in and out of classroom settings. Students are asked to take responsibility for their learning, while faculty members assume coaching and mentoring roles" [1]. We have certainly seen the collaboration aspect in our interdisciplinary student teams. For the purpose of this paper, we define an "interdisciplinary team" as the following: a project team comprised of students from both ETAC (engineering technology) and EAC (engineering) degree programs.

This paper will discuss the history and structure of our interdisciplinary PBL courses, our twosemester interdisciplinary industry-sponsored Capstone program, Capstone project examples, and data analysis of past projects.

\section{Brief History and Structure of Project Based Learning at WCU}

This year marks the $10^{\text {th }}$ anniversary of the implementation of our interdisciplinary PBL course sequence, required of all engineering and engineering technology majors at WCU. The PBL sequence was originally established by a team of engineering and engineering technology faculty to create a learning environment, and community of learners, that reflects how engineers work in the real world. Using their previous work experience, several ABET student learning outcomes, and the Industrial Advisory Boards' feedback as a guiding framework, the PBL sequence became the school's concerted effort to supply work-ready engineers who have had the opportunity to hone their professional skills through multiple linked courses requiring: written and oral communications; project management; open-ended problem solving; ethical and professional responsibilities; public health and safety; and an understanding of global, cultural, social, environmental, and economic factors.

PBL senior-level activities (Capstone) are carried out by the School of Engineering + Technology (SET) in conjunction with the Rapid Center in the College of Engineering and Technology (CET). These PBL efforts are strongly supported by the school faculty, which serve as faculty mentors on the various projects. The Rapid Center is the engagement arm of the CET, which connects students, faculty, and facilities with business and industry on real-world projects to help companies grow and to enhance the students' educational experience.

The five interdisciplinary PBL courses are ENGR 199, ENGR 200, ENGR 350, ENGR 400, and ENGR 450. These courses form project teams comprised of students from both engineering and engineering technology degrees: Electrical Engineering (EE), Electrical and Computer Engineering Technology (ECET), Engineering - Mechanical (BSE-M), Engineering - Electric Power (BSE-EP), and Engineering Technology (ET). Project teams focus on the design, prototyping, development, and testing of a wide variety of industry/government sponsored products and processes. These courses span all four years of the undergraduate program as 
indicated by their course numbers. The PBL nature of these courses is best described by their respective catalog descriptions:

\section{ENGR 199 - Introduction to Engineering Practices and Principles I}

An introduction to the engineering discipline. Group work, oral communication, problem solving, and the design process will be introduced through lecture and project-based learning activities. Contact Hours: 2 Lecture, 2 Lab.

\section{ENGR 200 - Engineering Practices and Principles II}

Engineering practices and principles, teaming, project planning, written communications, and conceptual design processes will be introduced through lecture and project-based learning activities. Contact Hours: 2 Lecture, 2 Lab.

\section{ENGR 350 - Engineering Practices and Principles III}

Engineering project-based learning (open-ended) with emphasis on project control and engineering design processes. Special emphasis will be placed on professional, ethical, global, environmental, and contemporary issues. Contact Hours: 2 Lecture, 2 Lab.

\section{ENGR 400 - Engineering Capstone I}

Senior engineering project selection, planning, and development. Emphasis will be placed on defining project requirements, developing project work breakdown structure, conceptual designs, and working prototypes. 1 Lecture, 4 Lab.

\section{ENGR 450 - Engineering Capstone II}

Senior engineering project design, development, fabrication, and testing. Emphasis will be placed on iterative design processes, project management and execution, fabrication and testing. 1 Lecture, 4 Lab.

In addition to providing a natural means of horizontal integration of student interdisciplinary cohorts, PBL provides other benefits [2],[3]. Most importantly, PBL creates natural living and learning communities that have been proven effective in student learning. According to Gablenick [4] et al., "Learning communities are curricular structures that link different disciplines around a common theme or question. They give greater coherence to the curriculum and provide students and faculty with a vital sense of shared inquiry." DeFour and Eaker [5] further argued that a learning community provides "an environment fostering mutual cooperation, emotional support, personal growth, and a synergy of efforts." Within the context of PBL, student cohorts and their faculty mentors have shared interest in solving a particular engineering problem. Our assessments and observations have shown that our PBL course sequence creates stronger bonds among student cohorts because they must work together for a common goal. The student cohorts (freshmen to seniors, to graduate students alike) more often work together, support each other (regardless of in-curricular or extra-curricular activities), and listen and learn from each other. Beyond the PBL course sequence, the overlap between major courses in engineering and engineering technology is minimal. The mechanical programs (ET and BSE-M) share two non-PBL engineering courses and the electrical programs (ECET and EE) also share two non-PBL engineering courses. 


\section{Structure of Two-semester Capstone Sequence (ENGR400 and ENGR450)}

The two-semester senior Capstone project is initiated at the start of the Fall semester with ENGR400 and completed at the end of Spring semester in ENGR450. During the prior summer, Capstone course instructors and Rapid Center staff recruit external industrial partners to sponsor projects. Site visits are commonly performed to better understand the proposed project's statement of work and adjust objectives and scope as needed. The project sponsor is responsible for providing a one-page statement of work including background, objectives, requirements, and deliverables. The activities of capstone projects typically span the ASME engineeringengineering technology continuum shown in Figure 1.

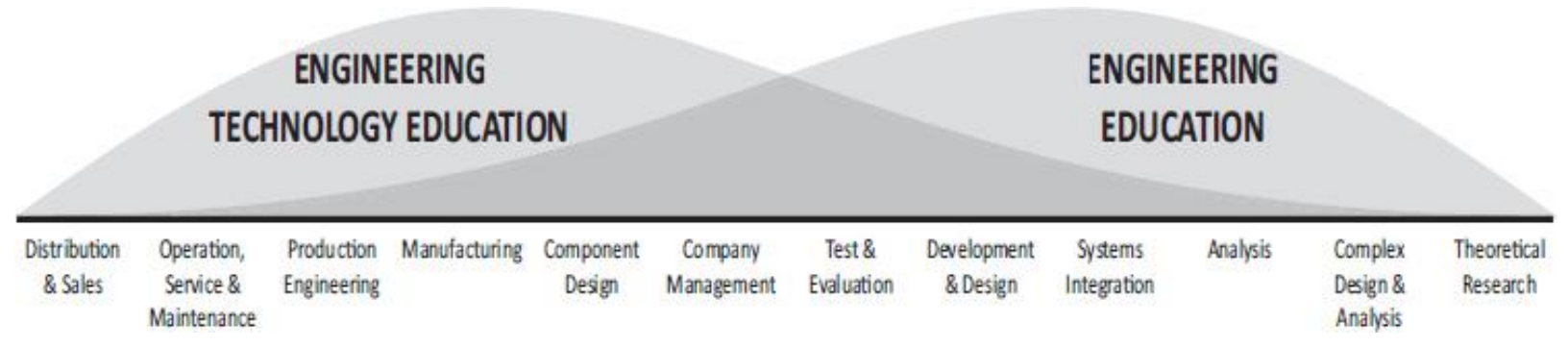

Figure 1. ASME engineering technology-engineering continuum model [6]

Each industrial sponsor is responsible for providing a mentor from their organization while WCU provides a faculty member to provide week-to-week mentorship. The one-page summaries for all projects are compiled into a project "catalog" that is distributed to students during the first week of ENGR400. Students are given the opportunity to rank their top four project choices, list one project that they do not want to be assigned, and provide any comments (up to 150 characters) that might be helpful when course instructors form teams. Students weigh many factors while identifying their preferred projects (e.g. employment prospects after graduation, interest in a particular industry, etc.), and are free to prioritize projects that are not best aligned with their major. Capstone teams typically consist of three to five students depending on the scope of the project. Project teams are defined on an ad-hoc basis by considering required disciplines (primarily whether the project has electrical and/or mechanical aspects), student preferences, and expected work breakdown.

Capstone projects follow a stage-gate process [7] in which the project is divided into four stages that each end with a project review with the sponsor that serves as a "gate." The four stages are described in detail below.

Stage 1 (Concept): The team works with the sponsor to finalize the statement of work and then develops the requirements matrix, risk analysis, preliminary project plan, and design concepts. Using an analysis-of-alternatives approach, a final concept is selected. The Concept gate review is completed during the first half of the Fall semester (ENGR400).

Stage 2 (Final Design): Based on the final concept, the team completes a detailed design. The term "design" can have a considerably different connotation depending on the project type (e.g. process improvement, prototype, engineering analysis, etc.). In this stage, the statement of work, 
requirements matrix, risk analysis, and project plan are updated. Additionally, the team identifies applicable standards and develops a testing plan for their project. The Final Design gate review is completed during the second half of the Fall semester (ENGR400).

Stage 3 (Implementation): During this stage, the team implements their project based on the final design developed in Stage 2. The goal of this stage is a working prototype, first demonstration, or initial analysis. Implementation must be completed by the middle of the Spring semester (ENGR450) to allow sufficient time for testing, qualification, and issue resolution.

Stage 4 (Validation): This stage provides the team with an opportunity to test or validate their project. Issues are expected, and some projects may require a second iteration or improvements in order to meet the sponsor's requirements. This stage is critical to ensuring quality deliverables and provides the team with insight into the rigorous testing and qualification requirements commonly found in engineering.

\section{Capstone Project Examples}

During the 2015 to 2019 academic years, 118 capstone projects were completed with 93 (79\%) being sponsored by external companies or individuals from a range of industries. Five project examples spanning the ASME continuum are described below.

Project 1: Non-Contact Laser Measuring System (GE Aviation, Asheville NC) Category: Process Improvement

GE Aviation is a provider of commercial, military, and general aviation jet and turboprop engines and components as well as avionics, electrical power, and mechanical systems for aircraft. The engineering Capstone team was challenged with developing a means of integrating semi-automation into a GapGun ${ }^{\mathrm{TM}}$ (non-contact laser profiling measurement tool). The student team integrated an industrial robotic manipulating arm with the laser profiling tool to produce repeatable measurements with improved capability at reduced cycle time.

Project 2: Rotor-Vane Assembly (Snap-On Tools, Murphy NC) Category: Automation

Snap-on is an American manufacturer of power tools and equipment for professional tool users. Several Snap-on pneumatic power tools incorporate a rotor with plastic vanes that allow for faster motor start-up and greater performance at high torque. The vanes are inserted into the rotor grooves manually, which is time-consuming. The vanes are also pre-soaked in oil which makes them difficult to sort and handle. The engineering Capstone team was tasked with developing an automated system to sort the vanes and load them into a magazine for easier handling. The team developed an automated system consisting of a vibratory sorting bowl and an electromechanically controlled magazine loading system. The magazines were designed to interface into a future automated work cell in which vanes would be loaded into the rotors.

Project 3: Development of Aerothermal Analysis Test Unit (USN FRC East, Cherry Point NC) Category: Test and Instrumentation

The Fleet Readiness Center (FRC) East, operated by the U.S. Navy, supports the sustainment of vertical lift aircraft by performing maintenance, repair, and overhaul functions on airframes, engines, and components. FRC East also provides engineering and logistics support to many 
Navy/Marine Corps platforms. Before newly constructed engine test cells are commissioned, an aerothermal analysis must be performed on the cell. This analysis provides the FRC with airflow and temperature data in the cell while the engine is running. The engineering capstone team developed a portable, rugged and watertight system with an array of pitot tubes and thermocouples for measurements at the intake and exhaust of the engine test cells, with data networking for real-time display in LabView ${ }^{\mathrm{TM}}$.

Project 4: Automated Eye Drop Dispenser (Medical Tool and Technology, Gainesville FL) Category: Prototype Development and Design Medical Tool and Technology is a product development company, focused principally on medical devices. The engineering capstone team was challenged to develop a medical device that accurately dispenses and regulates eye drops for patients without the dexterity to do so using standard handheld eye drop bottles. The student team designed and prototyped a goggle-based device. The device would measure positional orientation of the dropper bottle, provide a visual alert to the patient before the drop was delivered, and then precisely deliver a drop.

Project 5: Fiber Optics Communications Analysis of Mixed Signals and Signal Integrity (OCC, Roanoke VA)

Category: Engineering Analysis

Optical Cable Corporation (OCC) is a manufacturer of high-performance optical cable for communication systems. To better understand performance of their multi-mode fiber optics transceiver products in the field, OCC challenged the WCU engineering capstone team to measure and analyze bit error rate as a function of the condition of the fiber end. The student team characterized bit error rate and signal attenuation for a large array of clean-to-dirty fiber ends. The student team's results were deployed as a benchmark for technicians to use in field installation of optical fiber.

\section{Research Objective}

This paper analyzes historical data from the 2015-2016 to 2019-2020 academic years to better understand the most common types of projects, or project category (Process Improvement, Automation, Test and Instrumentation, Prototype, Engineering Analysis), and the typical composition of student teams for these categories. Faculty mentor and student perceptions of the effectiveness of interdisciplinary teams are surveyed to determine whether participants view interdisciplinary teams as the optimal solution for all project categories. These views on optimal team composition are compared to actual team composition from historical data. The results from this paper provide a framework for forming interdisciplinary Capstone teams.

\section{Methodology}

Capstone project and team data from 2015-2019 was tabulated. Each project was categorized by industry group and one of five project categories that span the ASME engineering technologyengineering continuum shown in Figure 1: Process Improvement, Automation, Test and Instrumentation, Prototype, and Engineering Analysis. All projects were assigned a primary project category and secondary project category. Projects might include aspects that fall into multiple categories, for example, a manufacturing process improvement project might require 
prototyping automation hardware. A judgement was made as to the project's primary category based on the statement of work, objectives, and sponsor intent. Likewise, some sponsors could be classified under multiple industry groups and some judgement was required to identify their primary industry.

Faculty that have participated directly in the WCU Capstone program and students currently enrolled in Capstone were eligible to participate in a newly developed survey that assessed their perception of the effectiveness of interdisciplinary teams for capstone projects. The survey generally asked whether teams comprised solely of engineering technology or engineering students would be more effective than an interdisciplinary team for different project categories. For example, for a project primarily involving hardware prototyping, participants were asked: "A team comprised solely of engineering technology students will outperform an interdisciplinary team, comprised of both engineering and engineering technology students, on a capstone project that is primarily within Prototype Development and Design functions within industry." This question was paired with a corresponding question that asked about the performance of engineering students on the same category of project: "A team comprised solely of engineering students will outperform an interdisciplinary team, comprised of both engineering and engineering technology students, on a capstone project that is primarily within Prototype Development and Design functions within industry." The pilot survey consisted of ten total questions, two for each Project Category. Respondents selected from a four-level scale: Strongly Agree, Somewhat Agree, Somewhat Disagree, Strongly Disagree. It was distributed electronically through Qualtrics and participation was strictly optional and not tied to an assignment or extra credit. 15 of 25 faculty, 26 of 45 engineering technology students, and 31 of 53 engineering students voluntarily participated in the survey. The overall student response rate $(58 \%)$ was reasonable and can be attributed to generally positive student-faculty relations. In future academic years, additional data will be collected using this survey instrument to validate its reliability.

\section{Data and analysis}

\section{Sponsor Industry Groups}

The western region of North Carolina is rapidly developing into a hub for advanced manufacturing [8]. This is reflected in Capstone project sponsorships by industry as shown in Table 1. Besides the Industrial and Scientific group which is a broad classification, sponsorships are relatively evenly distributed between electronics, aerospace, automotive, energy, and medical industries. Sponsors range from entrepreneurs to large multinational corporations. 
Table 1. Count and percentage of project sponsorships by industry

\begin{tabular}{|l|l|l|}
\hline Industry & Count & Percentage \\
\hline Industrial and Scientific & 29 & $25 \%$ \\
\hline Electronics & 17 & $14 \%$ \\
\hline Aerospace & 13 & $11 \%$ \\
\hline Energy & 12 & $10 \%$ \\
\hline Automotive & 11 & $9 \%$ \\
\hline Medical & 11 & $9 \%$ \\
\hline Other & 11 & $9 \%$ \\
\hline Defense & 8 & $7 \%$ \\
\hline Recreation & 6 & $5 \%$ \\
\hline
\end{tabular}

\section{Project Categories}

From 2015 to 2019, student teams completed 118 unique capstone projects. The projects were categorized based on the primary activity of the project. Table 2 shows the count and percentage of each project type over this time period. Prototype development (electronic, mechanical, or electromechanical) was the predominant category. Prototype development encompasses the Component Design and Development and Design activities that fall in the central overlapping region of the ASME continuum shown in Figure 1. Test and Instrumentation also falls near the center of this scale and accounted for $17 \%$ of projects. Process Improvement and Automation which lie towards the engineering technology end of the spectrum together accounted for $24 \%$ of projects. Engineering Analysis which lies towards the engineering end of the spectrum accounted for $18 \%$ of projects. In total, project categories in the overlap region in which interdisciplinary teams might be most effective accounted for $58 \%$ of projects.

Table 2. Count and percentage of each Project Category for the 2015 to 2019 academic years.

\begin{tabular}{|l|l|c|}
\hline Project Category & Count & Percentage \\
\hline Process Improvement & 20 & $16.9 \%$ \\
\hline Automation & 8 & $6.8 \%$ \\
\hline Test and Instrumentation & 20 & $16.9 \%$ \\
\hline Prototype & 49 & $41.5 \%$ \\
\hline Engineering Analysis & 21 & $17.8 \%$ \\
\hline
\end{tabular}

\section{Team Composition}

Capstone team data was analyzed to determine the percentage of projects that were comprised of both engineering and engineering technology students (\% ID) and the percentage of projects that were comprised of both electrical (ECET, EE) and mechanical (ET, BSE-M) degree programs (\%EM). Table 3 shows \%ID and \%EM by Project Category for projects completed during the 2015 to 2019 academic years. For all Project Categories besides Engineering Analysis, 70-88\% of teams were comprised of both engineering and engineering technology students. As shown in Table 4, 2015 had the lowest percentage of interdisciplinary teams (33\%) while 2019 had the 
highest (92\%). The ability to form interdisciplinary teams is impacted by relative enrollment in engineering and engineering technology programs. Table 5 shows the number of students in each degree program and the percentage of students in engineering and engineering technology degrees. In 2015, the Capstone class was strongly skewed towards engineering technology students $(81 \%)$ and not surprisingly the percentage of interdisciplinary teams that year was low (33\%) due to relatively few engineering students. In 2016 the first cohort of students in a newly created BSE-M program reached their senior year, and this coupled with an increase in EE students resulted in a more balanced capstone class (E: 42\%, ET: 58\%). Forming interdisciplinary teams is straightforward with a balanced class. From 2017-2019, the relative percentage of engineering and engineering technology students has remained balanced; however, steady growth in the BSE-M program has gradually shifted the majority to engineering. This trend is expected to continue and will impact capstone team formation in future years. While recruiting industry sponsors and defining projects, it will be important to ensure that the distribution of Project Categories matches the expected distribution of student disciplines.

Table 3. Percentage of projects with interdisciplinary teams (\%ID) and both electrical and mechanical degree programs (\% EM) by Project Category

\begin{tabular}{|l|c|c|c|}
\hline Project Category & Project Count & \% ID & \% EM \\
\hline Process Improvement & 20 & $70 \%$ & $40 \%$ \\
\hline Automation & 8 & $88 \%$ & $50 \%$ \\
\hline Test and Instrumentation & 20 & $75 \%$ & $75 \%$ \\
\hline Prototype & 49 & $78 \%$ & $59 \%$ \\
\hline Engineering Analysis & 21 & $48 \%$ & $29 \%$ \\
\hline
\end{tabular}

Table 4. Percentage of projects with interdisciplinary teams (\%ID) and both electrical and mechanical degree programs (\% EM) by project year

\begin{tabular}{|c|c|c|c|}
\hline Year & Project Count & \% ID & \% EM \\
\hline 2015 & 21 & $33 \%$ & $38 \%$ \\
\hline 2016 & 26 & $81 \%$ & $62 \%$ \\
\hline 2017 & 22 & $73 \%$ & $50 \%$ \\
\hline 2018 & 25 & $72 \%$ & $60 \%$ \\
\hline 2019 & 24 & $92 \%$ & $50 \%$ \\
\hline
\end{tabular}

Table 5. Number of Capstone students in each degree program and percentage of students in engineering and engineering technology degrees by academic year

\begin{tabular}{|c|c|c|c|c|c|c|c|}
\hline Year & BSE-M & ET & EE & ECET & Total Students & \%E & \%ET \\
\hline 2015 & 0 & 34 & 11 & 12 & 57 & $19 \%$ & $81 \%$ \\
\hline 2016 & 11 & 33 & 27 & 20 & 91 & $42 \%$ & $58 \%$ \\
\hline 2017 & 27 & 39 & 12 & 13 & 91 & $43 \%$ & $57 \%$ \\
\hline 2018 & 28 & 32 & 21 & 16 & 97 & $51 \%$ & $49 \%$ \\
\hline 2019 & 33 & 31 & 20 & 14 & 98 & $54 \%$ & $46 \%$ \\
\hline
\end{tabular}


Figure 2 shows the average composition of teams by Project Category for the 2016-2019 academic years. The first cohort of BSE-M students reached their senior year in 2016; therefore, data from 2015 was excluded. As might be expected, engineering technology students accounted for approximately two-thirds of the students assigned to Process Improvement and Automation projects. Test and Instrumentation and Prototype projects were more evenly split between disciplines with $56 \%$ and $50 \%$ of the students coming from engineering technology programs. For Engineering Analysis projects, two-thirds of students were enrolled in engineering degree programs.

\section{E/ET}

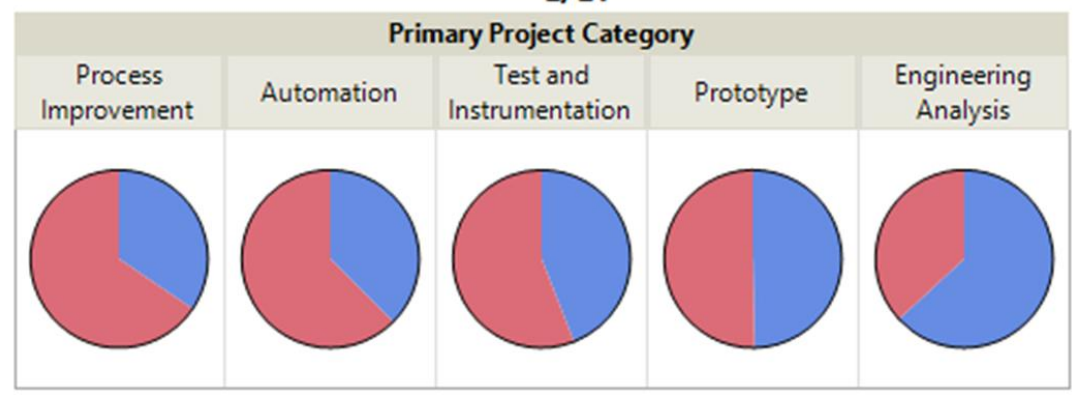

E/ET

IE

ET

Figure 2. Average composition of teams from 2016-2019 by Project Category. Blue indicates percentage of engineering students (BSE-M, EE) and red indicates percentage of engineering technology students (ET, ECET). The first cohort of BSE-M students was ready for senior capstone in 2016, hence data from 2015 was excluded.

\section{Perception Survey Results}

Students and faculty were surveyed to determine whether a single discipline team (E-Only: comprised only of engineering students, or ET-Only: comprised only of engineering technology students) would outperform an interdisciplinary team for certain types or categories of projects (Process Improvement, Automation, Test and Instrumentation, Prototype, and Engineering Analysis). This results in ten survey questions answered by three respondent groups: engineering technology students (ET), engineering students $(E)$, and Faculty. Each mean diamond in Figure 3 represents the response to one of these questions by a particular respondent group. For example, the first three mean diamonds show whether the three respondent groups agree or disagree with the statement: A team solely comprised of engineering students will outperform an interdisciplinary team on a Process Improvement project. The tips of the mean diamonds indicate the $95 \%$ confidence interval on the response; therefore, non-overlapping mean diamonds are statistically different with $95 \%$ confidence. Mean diamonds overlapping the neutral level are interpreted as indicating that the respondent group neither agreed or disagreed with the statement. Mean diamonds that show a statistically significant level of agreement with the statement are highlighted in green while diamonds showing a statistically significant level of disagreement are highlighted in red. 


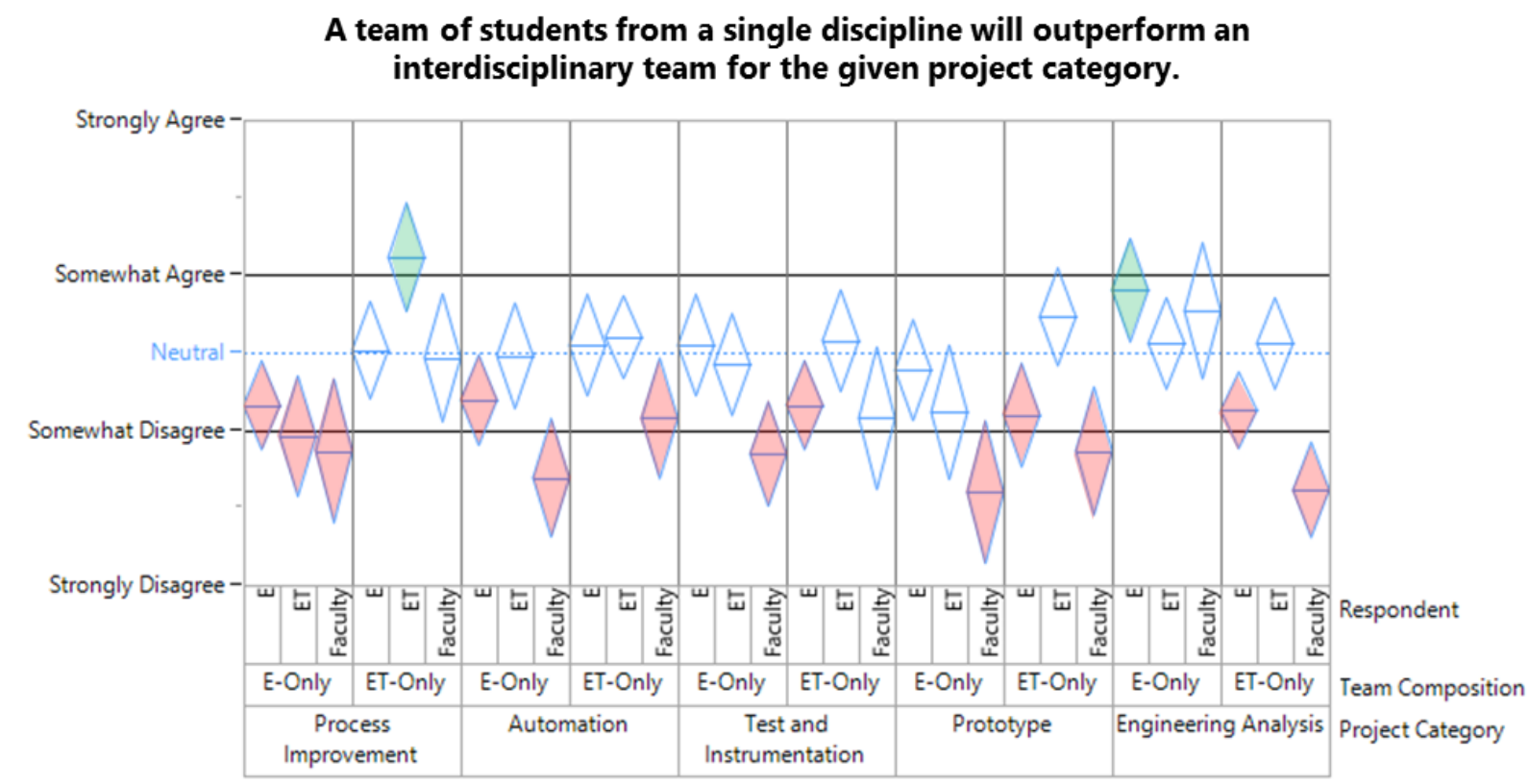

Figure 3. Survey results for whether a team comprised of students from a single discipline (Eonly or ET-only) will outperform an interdisciplinary team for the given Project Category. Survey results are grouped by respondent type (E= Engineering student, ET= Engineering Technology student, Faculty). The mean diamonds show the upper and lower bounds with $95 \%$ confidence.

For the Process Improvement category, all respondent groups disagreed that an E-Only team would outperform an interdisciplinary team, while only engineering technology students agreed that an ET-only would outperform an interdisciplinary team.

For the Automation category, faculty disagreed that either type of team (E-Only, ET-only) would perform better thus signaling a preference of interdisciplinary teams. Engineering students also disagreed that an E-only team would perform better in this category.

For the Test and Instrumentation category, faculty disagreed that an E-only team would be preferred while engineering students disagreed that an ET-only would perform better.

For the Prototype category, faculty disagreed that either type of team (E-Only, ET-only) would perform better thus signaling a preference of interdisciplinary teams. Engineering students also disagreed that an ET-only team would be an optimal solution for a prototype development project.

For the Engineering Analysis category, engineering students showed a preference for E-only teams. Both engineering students and faculty disagreed that an ET-only team would be the best fit for this category.

It is instructive to examine aggregate results by combining all respondents into a single group (Figure 4) and combining all project categories into a single group (Figure 5). From Figure 4, and as summarized in Table 6 , the respondent group as a whole preferred engineering technology 
teams for Process Improvement projects, engineering teams for Engineering Analysis projects, and interdisciplinary teams for the remaining Project Categories. These survey results are consistent with the ASME continuum shown in Figure 1. Additionally, Figure 5 shows that engineering technology students have a higher level of perceived self-efficacy (averaged across all five Project Categories) compared to engineering students.

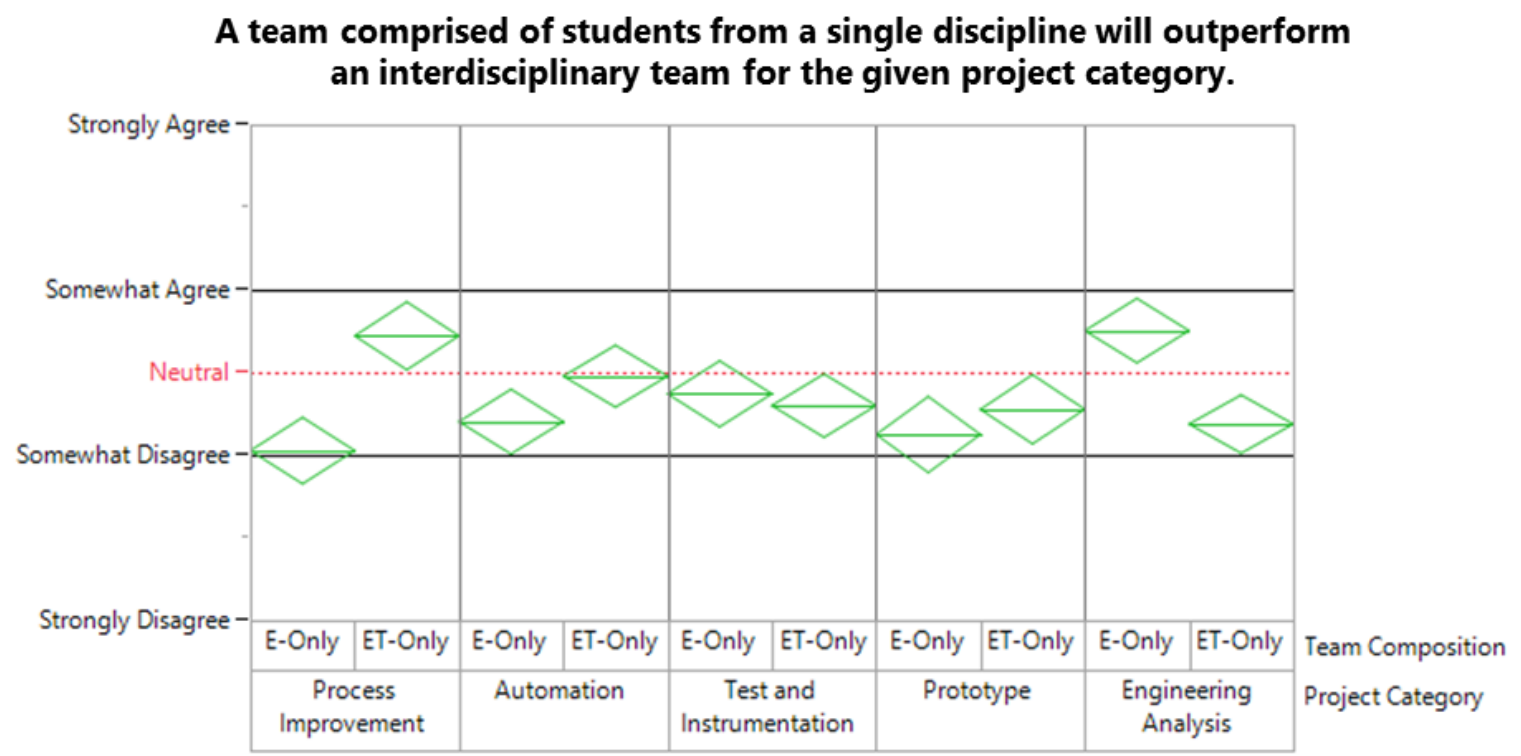

Figure 4. Survey results for whether a team comprised of students from a single discipline (E-only or ET-only) will outperform an interdisciplinary team for the given Project Category. Responses from all respondents were combined into single group. The mean diamonds show the upper and lower bounds with $95 \%$ confidence.

A team comprised of students from a single discipline will outperform an interdisciplinary team.

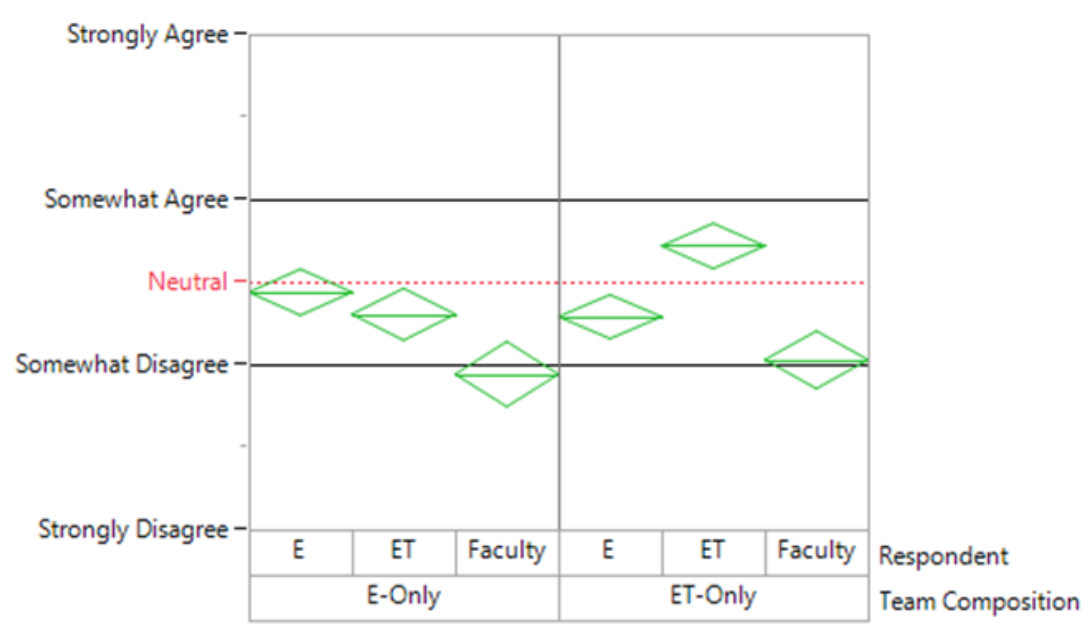

Figure 5. Survey results for whether a team comprised of students from a single discipline (E-only or ET-only) will outperform an interdisciplinary team on average (all Project Categories combined into single group). Survey results are grouped by respondent type (E= Engineering student, ET= Engineering Technology student, Faculty). The mean diamonds show the upper and lower bounds with $95 \%$ confidence. 
Table 6. Summary of Overall Team Composition Preference by Project Category with all respondents combined into single group.

\begin{tabular}{|l|c|}
\hline Project Category & $\begin{array}{c}\text { Team Composition } \\
\text { Preference }\end{array}$ \\
\hline Process Improvement & ET-only \\
\hline Automation & Interdisciplinary \\
\hline Test and Instrumentation & Interdisciplinary \\
\hline Prototype & Interdisciplinary \\
\hline Engineering Analysis & E-only \\
\hline
\end{tabular}

\section{Conclusions}

Capstone students and faculty mentors perceived interdisciplinary teams as being most effective for Automation, Test and Instrumentation, and Prototype projects, with engineering technology teams and engineering teams being more effective for Process Improvement and Engineering Analysis projects, respectively. Faculty on average favored interdisciplinary teams. These survey results are consistent with the ASME engineering technology-engineering continuum model and suggest that it provides a useful framework for forming interdisciplinary student teams.

Based on analysis of projects from the 2015-2019 academic years, 65\% of projects fell into Project Categories most well suited for interdisciplinary teams, with the remaining $35 \%$ being split between Process Improvement (17\%) and Engineering Analysis (18\%) projects.

With $65 \%$ of recruited capstone projects falling into categories best suited for interdisciplinary teams and senior classes being approximately evenly distributed between engineering and engineering technology degrees, team formation has historically been relatively straightforward. With the trend towards a higher percentage of engineering students, and no guarantees regarding future Project Categories, a more systematic and strategic method for Capstone team formation might be required. This could include recruiting specific types of projects, forming single discipline teams when beneficial, and attempting to maintain a balance between enrollment in engineering and engineering technology degree programs.

\section{References}

[1] R. Vaz, "High Impact Practices Work.” Accessed: January 26, 2020. [Online]. Available: https://www.insidehighered.com/views/2019/06/04/why-colleges-should-involve-more-studentshigh-impact-practices-opinion

[2] W.N. Bender, Project-Based Learning: Differentiating Instruction for the 21st Century. Thousand Oaks, CA: Corwin Press, 2012.

[3] S. Boss and J. Krauss, Reinventing Project-Based Learning. Eugene, OR: International Society for Technology in Education, 2007. 
[4] F. Gablenick, J. McGregor, R. S. Matthews, and B. L. Smith, Learning Communities: Creating, Connections Among Students, Faculty, and Disciplines. San Francisco, CA: JosseyBass Inc, 1990.

[5] R. DeFour and R. Eaker, Professional Learning Communities at Work: Best Practices for Enhancing Student Achievement. Bloomington, IN: National Education Service, 1998.

[6] National Academy of Engineering, Engineering Technology Education in the United States. Accessed: December 11, 2019. [Online]. Available: https://doi.org/10.17226/23402

[7] R. Cooper, "Stage-Gate Systems: A New Tool for Managing New Products," Business Horizons, pp. 44-54, May/Jun. 1990.

[8] M. Hunt, M. (2016) "How advanced manufacturing is transforming WNC's economy," Accessed: January 30, 2020. [Online]. Available: https://mountainx.com/news/how-advancedmanufacturing-is-transforming-wncs-economy/ 